\title{
The Application of Fractal Analysis on Thyroid Ultrasound Images
}

\section{Tiroid Ultrason Görüntülerinde Fraktal Analiz Uygulamas1}

\author{
Ebru Aydındağ Bayrak ${ }^{1}$ (D, Pınar Kırcı² (i)
}

'Istanbul University Cerrahpaşa, Department of Engineering Sciences, İstanbul, Turkey ${ }^{2}$ Istanbul University Cerrahpaşa, Department of Engineering Sciences, İstanbul, Turkey

ORCID: E.A.B. 0000-0002-2637-9245; P.K. 0000-0002-0442-0235

\section{Corresponding author:}

Pinar Kirc1,

Istanbul University Cerrahpaşa, Department of

Engineering Sciences, İstanbul, Turkey

Telephone: +90 212473 7070-17826

E-mail address: pkirci@istanbul.edu.tr

Submitted: 12.12 .2018

Revision Requested: 26.12 .2018

Last Revision Received: 02.12.2019

Accepted: 31.07 .2019

Citation: Aydındağ Bayrak, E., \& Kırcı, P. (2019). The application of fractal analysis on thyroid ultrasound images. Acta Infologica, 3(2), 83-90. https://doi.org/10.26650/acin.496129

\begin{abstract}
The concept of fractals is used for complex and irregular objects or structures in systems. The complexity of medical images allows us to use Fractal geometry rather then Euclidian geometry for their characterization. In this paper, we have discussed the analysis of thyroid ultrasound images to calculate fractal dimension. Fractal analysis software was used for the calculation of fractal dimension and correlation coefficient values. In the fractal analysis on the thyroid ultrasound images, the determination of the dimensions of the lesions, nodules or cysts in the region by using fractal concepts can be predicted and used as an assistive system for physicians in the treatment and early diagnosis of thyroid disorders.
\end{abstract}

Keywords: Fractal Analysis, Box Counting Method, Fractal Dimension

öz

Fraktal kavramı, sistemlerdeki karmaşık ve düzensiz nesneler veya yapılar için kullanılmaktadır. Medikal görüntülerin karmaşıklığı, görüntülerin karakterizasyonu için Öklid geometrisi yerine Fraktal geometrisini kullanmamıza izin verir. Bu çalışmada, tiroid ultrason görüntüleri fraktal boyutu hesaplamak için analiz edilmiştir. Fraktal analiz yazılımı, korelasyon katsayısının ve fraktal boyut değerlerinin hesaplanması için kullanılmıştır. Hesaplanan fraktal boyut değerleri tiroid ultrason görüntü verisine göre değişmektedir. Tiroid ultrason görüntülerinde fraktal analiz ile bölgede yer alan kistlerin, nodüllerin veya lezyonların fraktal kavramı kullanılarak boyutlarının hesaplanmasının, tiroid hastalıklarının erken teşhis edilmesinde ve tedavisinde hekimlere yardımcı sistem olarak kullanılabileceği öngörülmektedir.

Anahtar kelimeler: Fraktal Analiz, Kutu Sayma Yöntemi, Fraktal Boyut 


\section{INTRODUCTION}

When Mandelbrot (1967) studied the length of the coastline using different rulers, he recognized that the length of the coastline increased unlimitedly as the size of the ruler decreased. He explained this situation using the concept of fractals.

Fractals can be described as a geometric form that can be divided into non-uniform which is repetitive when divided into smaller parts (Mandelbrot, 1983).

Fractal geometry is a mathematical notion that can be used to measure structures and systems that are inadequately represented by Euclidean geometry. It might be a useful additional parameter for classifying biological structures. Fractals are characterized by their properties - self-similarity, scaling and scale-invariance (Lennon et al., 2015).

Medical images are irregular and complex objects. Because of these reasons, Fractal geometry can be preferred over Euclidean geometry for medical image characterization. Fractal analysis methods and tools can be used for medical diagnosis.

In this study, the fractal analysis of thyroid ultrasound images was completed using a Computer Aid Diagnosis (CAD) technique for prediction and early detection of thyroid diseases. The increase or decrease in fractal dimensions obtained from the thyroid images can be used as an indicator of the course of thyroid disorders.

The present paper is organized as follows. In Section 2, related works are explained. In Section 3, the utilized methods are presented and the box counting method is defined. In Section 4, a proposed system is given and fractal analysis software is presented. The scenarios and findings are presented in Section 5. The paper ends in a discussion and concluding remarks and proposals.

\section{RELATED WORKS}

Fractal geometry was used to estimate the complexity and irregularity of forms and patterns that were observed in lung tumour growth in Lennon et al., (2015). In their study, sequential Computer Tomography (CT) images of a patient who declined treatment, were analyzed with Image J fractal analysis software and showed the progressive tumour growth in five years. Fractal dimension values increased over 5 years. Similarly, they wanted to check the response to the treatment and studied CT images of the patient, pretreatment and post-treatment. The fractal dimension of the pre-treatment tumor areas was 1.1237 and decreased by 0.064 to 1.0597 post-treatment.

Hadzieva, Bogatinoskai Shuminoska and Petroski (2017) analysed a set of 100 images of melanoma, and the fractal dimension was calculated with distinct estimators for the contours. They analyzed more than 10 different examples of software to estimate fractal dimension with the box counting method. They found the five best are Harfa, Fraclac, Fractalyse, Fractal Count and Fractal Analysis System. Also, they calculated the averages, the standard deviations, the medians, the minimal and the maximal for the five cases. They explained that the two sets of fractal dimensions of melanoma and non-melanoma moles were not statistically different.

Chakravarty and Chakraborty (2017) studied fractal analysis related to tumor growth in human lungs using Computer Tomography (CT) scan images. They explained that to obtain a result with any variance on the number of pixels of an image, the fractal dimension values are changed.

Lupo, Leguto, Bortolato and Korol (2016) studied the incubation of human red blood cells with Ascaris lumbricoides and Trichinella spiralis muscle larvae extracts using Fractalyse software. Fractalyse has been used to develop a beneficial technique for the detection of red blood cells membrane modifications.

Uahabi and Atounti (2015) studied the contribution of fractals in the diagnostics of diabetic retinopathy. They analyzed two sample groups, one is normal and the second is pathological. Each sample had 10 retinal images and fractal dimensions were calculated for each sample with the box counting algorithm. A comparison of the fractal dimension values in the two sample groups have a significant result that normal and pathological retina are quite different from each other. They explained that this information can be used as a non-invasive technique for early detection of retinal diseases. 
Acharya et al. (2014) reviewed different studies on automated computer aided diagnostics of thyroid cancer according to benign and malignant types. They discussed two different types of features that are used to analyze benign and malignant thyroid nodules. They are grouped as sonographic features from the ultrasound images and the non-clinical features extracted from the ultrasound images using statistical and data mining methods. The most sensitive detection methods for thyroid nodules were categorized with fine-needle aspiration biopsy, computed tomography, magnetic resonance imaging, ultrasound imaging, elastography and pathologic studies.

Voinea and Popescu (2011) chose to use the fractal technique in an analysis of electronographic images because the electronographic images have fractal features. Although there are many assessment technologies for fractal dimensions, they used the box counting algorithm to calculate fractal dimension. In their study, other methods and algorithms were used like Fractalyse 2.4, Benoit and Fractop. A total of 15 algorithms were investigated in the aforementioned 3 software systems. At the end of the study, it was found that for most algorithms, the relative errors on average were below $5 \%$.

Savelonas, Maroulis and Sangriotis (2009) studied a novel computer-based approach for malignancy risk assessment of thyroid nodules in ultrasound images. The malignancy risk features of the proposed approach are based on compactness, fractal dimension and local echogenicity variance. The k Nearest Neighbor (kNN) and Support Vector Machine (SVM) are used as a classifier and SVM has showed higher classification performance when compared to kNN.

Lv, Guo, Wang, Zhang and Fang (2009) used fractal analysis in Magnetic Resonance (MR) images to computerize the characterization of prostate cancer. For this study 55 T2-weighted images were collected and split into two groups: the first group had prostate cancer (27 patients) and the second group had no histological abnormality (28 patients). At the end of the study, they explained that fractal features can assure helpful MR based quantitative indicators for enhancing the identification and localization of prostate cancer.

Timbo, Rosa, Goncalves and Duarte (2009) explained the use of software to describe cell anomaly through their fractal dimension calculation for cancer diagnosis. The cell's electronic microscopic image was converted to a black and white format to calculate fractal dimension. The number of black pixels on the image contour was determined and these pixels were used for the box counting algorithm. For a single cell, fractal dimension was calculated as 1.28.

MacGillivray, Patton, Doubal, Graham and Wardlaw (2007) used fractal dimension to measure the complexity of the retinal vascular network. Fractal analysis was performed on skeletonized versions of the network in 40 images obtained in another study about strokes. In this study they described a technique for fractal analysis. It was based on post-processing digital fundus images to automatically segment blood vessels and measure the fractal dimension of vascular skeletons.

\section{UTILIZIED METHOD}

\subsection{The Box Counting Method}

In the box counting method, the object is covered by a grid of squares where initially the side length is $\mathrm{rl}$ then the number of N1 of squares that include the part of the object are counted. The square is then divided by two, the square's side length is then $\mathrm{r} 2$ and the number of $\mathrm{N} 2$ of squares which include the part of the object are then counted. This step is repeated $\mathrm{M}$ times and the square's side length is made shorter for every step. The relationship between $\mathrm{N}$ and $\mathrm{r}$,

$\log \left(N\left(r_{i}\right)\right)=\mathrm{a}-D \log \left(r_{i}\right)$

fractal dimension (D) is calculated as the slope of fitting the regression line between the independent variable $\log \left(r_{i}\right)$ and the dependent variable where $\log \left(N\left(r_{i}\right)\right)($ Gonzato, 1998).

The box counting method is among the most commonly used techniques to calculate the fractal dimension of objects and systems. Firstly, the number of boxes N(r), each of different side length of box $r$ that are covered the object is counted. For the side length of box $r=1$, the box covers all of the object. For $r=1 / 2$, the box is divided by four and for $r=1 / 4$, the box is divided by sixteen. This process is repeated many times and then the graph of the $\log (\mathrm{Nr})-\log (1 / \mathrm{r})$ relationship is plotted and a regression line is fitted to this graph. The slope of the regression line gives us the estimated fractal dimension (Fig. 1). 

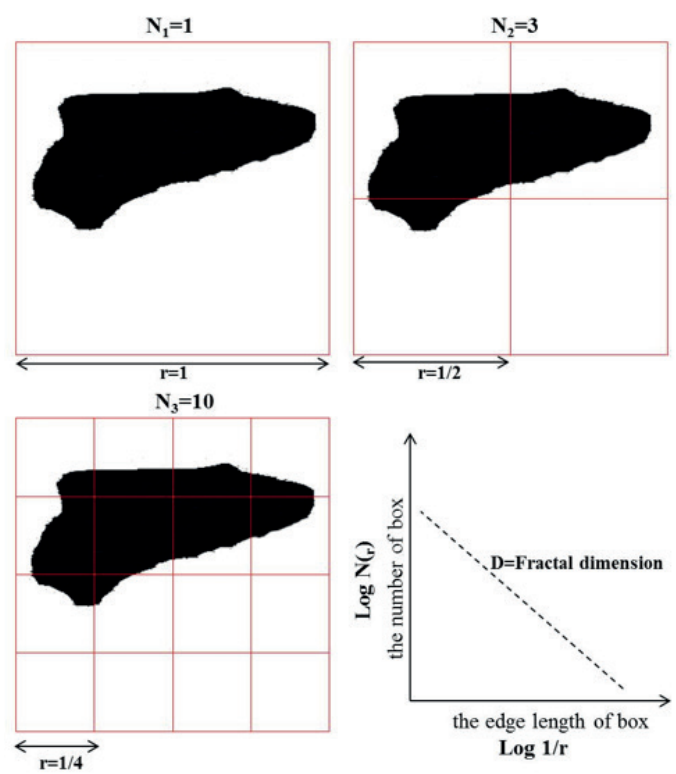

Figure 1. The box counting method applied on thyroid ultrasound images was represented as schemes. In the box counting method, the relationship between the number of these boxes which is $\mathrm{N}(\mathrm{r})$ and the side length of box $\mathrm{r}$ which cover an object is used for the estimation of fractal dimension.

\section{PROPOSED METHOD}

\subsection{Materials}

Thyroid B-mode ultrasound images were obtained from open access Thyroid Digital Image Database (TDID). The dataset was comprised of the diagnostic description of suspicious thyroid lesions by expert radiologists. Several types of thyroid lesions were included in the database e.g. thyroiditis, cystic nodules, adenomas and thyroid cancers. Also, the malignant lesions were confirmed by biopsy (Thyroid Digital Image Database, n.d.).

The TDID is a public open access dataset and it consists of uncompressed JPEG images and XML files. The main purpose of the the TDID dataset is to develop algorithms for using computer aid systems in the analysis and diagnosis of thyroid nodules. It contains the analysis of 347 thyroid ultrasound images, performed by two experts in 299 patients ( 270 female and 20 male whose ages varied $57.35 \pm 16.2$ years) with thyroid disease. The patients were classified by the experts using the Thyroid Imaging Reporting and Data System (TIRADS) and 200 cases were confirmed by BETHESDA System (System for Reporting Thyroid Cytopathology). There were 137 thyroiditis and goiter cases and 18 cases of spongiform nodules. Papillary and follicular cancers were identified in 21 patients. In 24 cases, the samples were not enough for the pathology study (Pedreza et al., 2015).

TIRADS system categories can be explained as following (Ashamallak \& EL-Adalany, 2016);

(1) Normal thyroid,

(2) Benign lesion,

(3) Probably Benign (No suspicious ultrasound feature),

(4) Moderately suspicious,

(4a) One suspicious ultrasound feature,

(4b) Two suspicious ultrasound features,

(4c) Three or four suspicious ultrasound features,

(5) Higly suspicious (Five suspicious features for malignant). 


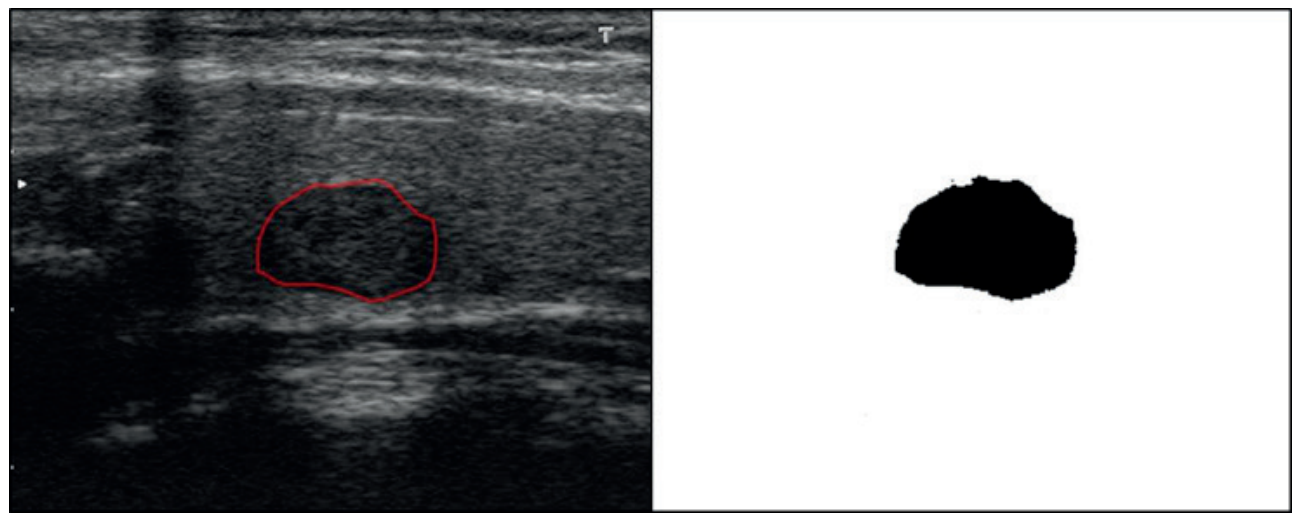

Figure 2. Thyroid ultrasound images were converted to a black and white format to use in the fractal analysis software tool. The nodule's information consists of composition, echogenicity, shape, margins, classifications, TIRADS score and BETHESDA System (Thyroid Digital Image Database, n.d.).

\subsection{Method}

The analysis of thyroid ultrasound images is more important for the early detection of thyroid disorders. Goiter, cancer, nodules or thyroiditis are more common disorders in the thyroid and any development in their early diagnosis has a lifesaving role. As medical images are complex and irregular objects, they have fractal features and so fractal analysis methods can be used for their analysis. Also, Fractal geometry can be prefered over Euclidean geometry to make better medical image characterization.

In the analysis of the thyroid ultrasound images data, the box counting method was performed using Fractalyse Analysis 2.4 Software. This software is an image analysis program developed by the "Mobility, city and transport" research team of the Thema Research Center in France (Hadzieva et al., 2016).

Fractalyse is a free software and has a simple interface. It was developed to count the fractal dimension of the area of cities. Black and white images, curves and networks were used to estimate fractal dimension. The images must be binary in TIFF (Tagged Image File Format) or BMP (Bitmap) file formats. In the procedure for calculating fractal dimension using the box counting method, counting and estimation modules were used. The counting module offers an option to determine box size and chosen algorithm type. The box size can be chosen as either exponential or linear (Fractalyse, n.d; Thema n.d.).

In the paper, we chose to use the box counting method. There are two modules in the fractal analysis software to calculate fractal dimension with the box counting method. The first module is the Grid, the second is the Free Box method. The Grid Method is the most used method for estimating fractal dimension. The image is covered by a quadratical grid and the grid distance $\varepsilon$ is then varied (Fig. 3). The Free Box Method is a generalized version of the grid method. This method is based on finding the least number of squares of size $\varepsilon$ needed to cover all the black pixels (Fig. 4).

The basic procedures for the calculation of fractal dimension using Fractalyse software can be summarized as follows:

Step 1: Thyroid ultrasound image acquisition and processing.

Step 2: The thyroid ultrasound images were converted to binary (black and white) format and processed.

Step 3: Fractal dimension was calculated from the binary images. 


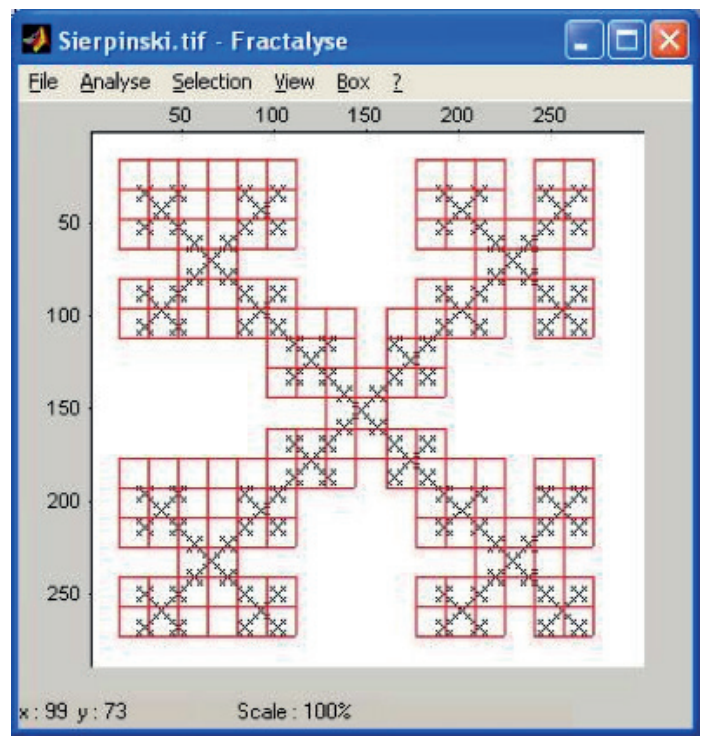

Figure 3. The Grid method application of the Sierpinski carpet (Fractalyse, n.d.).

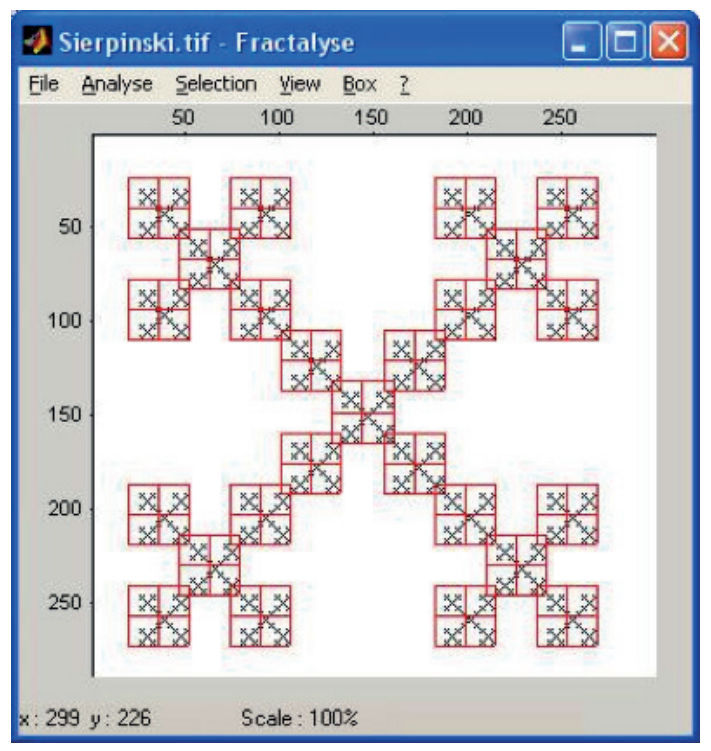

Figure 4. The Free Box method application of the Sierpinski carpet. The black pixels of object are covered by the least number of squares in contrast to the Grid method (Fractalyse, n.d.).

\section{FINDINGS}

In the study, the box counting method was utilized in the Fractalyse software in two ways. The Grid and Free Box methods were used to estimate fractal dimensions. For every thyroid ultrasound image, fractal dimension and correlation coefficient values were calculated with the fractal analysis tool (Fig. 5 and Fig. 6). In the applied box counting method, different fractal dimension values were calculated according to thyroid ultrasound image data. The correlation coefficient values (R) obtained were to 1 . 


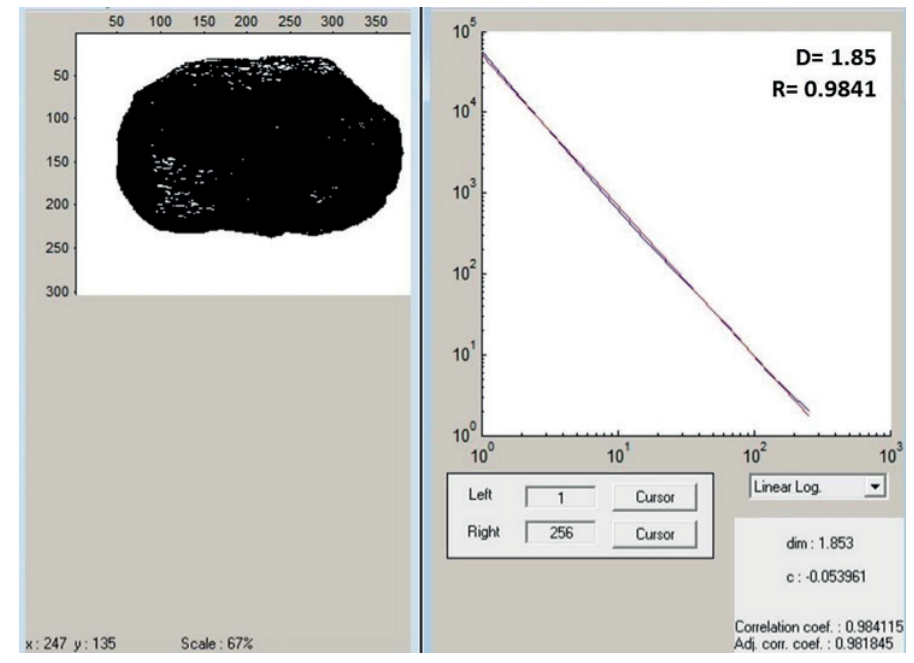

Figure 5. A result of Grid method application for a benign thyroid ultrasound image. The fractal dimension value and correlation coefficient are shown.

Fractal dimension and correlation coefficient values are shown. The fractal dimension of a benign thyroid lesion was calculated in the box from the Grid method given in Fig. 5. The fractal dimension of a malignant lesion was obtained in the box from the Free Box method given in Fig. 6. Furthermore, the range of fractal dimension values for benign and malignant thyroid images are given in Table 1.
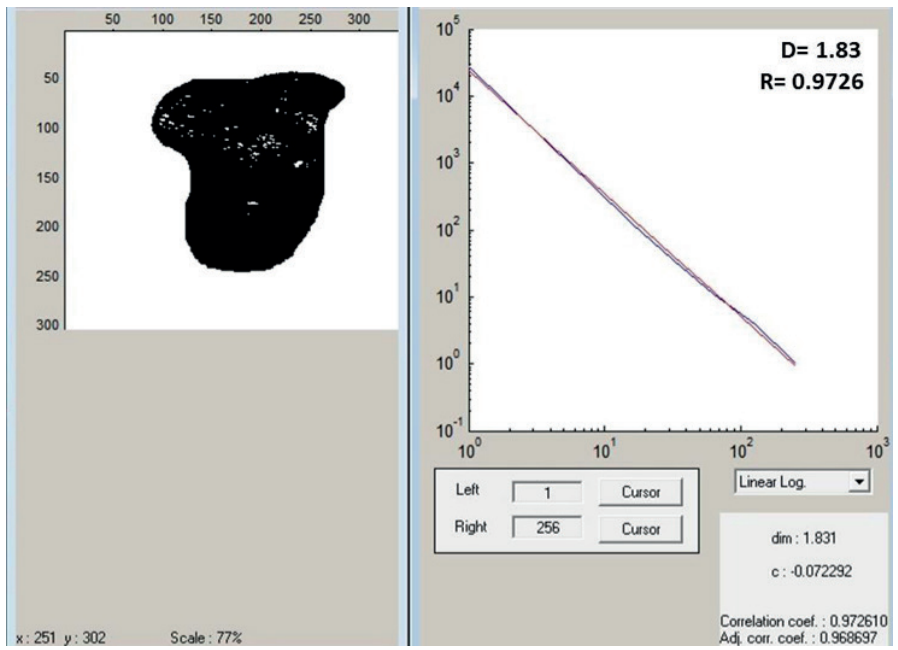

Figure 6. A result of Free Box method application for a malignant thyroid ultrasound image. The fractal dimension value and correlation coefficient are shown.

Table 1

The range of fractal dimension values for benign and malignant thyroid image data.

\begin{tabular}{ccc}
\hline & \multicolumn{3}{c}{ The range of fractal dimension values } \\
\cline { 2 - 3 } Benign thyroid lesion & Grid Method & Free Box Method \\
Malignant thyroid lesion & $1.64<\mathrm{D}<1.85$ & $1.71<\mathrm{D}<1.86$ \\
\hline
\end{tabular}

\section{DISCUSSION AND CONCLUSION}

The human body and organs have been shown as having a fractal structure. Our lungs, vessels, neurons and organs in particular can be given as examples of basic fractal norms in the human body. For this reason, we have used a fractal analysis tool for the characterization of thyroid ultrasound images. For early detection of thyroid disorders, the analysis of thyroid ultrasound images has a significant role. 
In the present work, thyroid ultrasound images were analyzed to estimate fractal dimension. The Grid and Free Box method were the two approaches used with the Fractalyse Image Analysis Software. Fractal dimension values generally range from 1.59 to 1.86 . The correlation coefficients were calculated in the range of $0.8676-0.9841$ for the Grid and Free Box methods. The fractal dimension values were calculated separately for benign and malign cases presented in the thyroid digital ultrasound database. For the benign thyroid ultrasound images, fractal dimensions were calculated in the range of 1.64- 1.86. The fractal dimensions of the malign thyroid ultrasound images were obtained in the range of 1.59-1.71.

The fractal analysis of thyroid ultrasound images can be used as a Computer Aid Diagnosis (CAD) technique for the prediction and early detection of thyroid diseases. For example, thyroid lesion (benign or malignancy) growths can be monitored looking at the fractal dimension of the lesion using fractal analysis on sequential ultrasound images of thyroid patients. The increase or decrease in fractal dimension obtained from the thyroid images may be used as an indicator of the course of thyroid disorders. Additionally, tumour area, the size of nodules, cysts or lesions can be calculated using fractal analysis of thyroid ultrasound images and the fractal dimensions can be compared pre-treatment and post-treatment. In this way, the accuracy and success of treatment may be evaluated.

Grant Support: The author received no financial support for this work.

\section{REFERENCES}

Acharya, U. R., Swapna, G., Sree, S. V., Molinari, F., Gupta, S., Bardales, R. H.... Suri, J. S. (2014). A review on ultrasound-based thyroid cancer tissue characterization and automated classification. Technology in Cancer Research \& Treatment, 13(4), 289-301. https://doi.org/10.7785/tcrt.2012.500381

Ashamallah, G. A., \& EL-Adalany, M. A. (2016). Risk for malignancy of thyroid nodules: Comparative study between TIRADS and US based classification system. The Egyptian Journal of Radiology and Nuclear Medicine, 47(4), 1373-1384. https://doi.org/10.1016/j.ejrnm.2016.08.021

Chakravarty, S. P., \& Chakraborty, S. (2017, December). Fractal analysis related to tumour growth in lungs: A review. In 2017 Fourth International Conference on Image Information Processing (ICIIP) (pp. 1-4). IEEE. https://doi.org/10.1109/ICIIP.2017.8313752

Fractalyse Analysis Software. (2018, November 05). Retrieved from http://www.fractalyse.org/

Gonzato, G. (1998). A practical implementation of the box counting algorithm. Computers \& Geosciences, 24(1), 95-100.

Hadzieva, E., Bogatinoska, D. C., Petroski, R., Shuminoska, M., Gjergjeska, L., Karadimce, A., \& Trajkova, V. (2016). Is the fractal dimension of the contour-lines a reliable tool for classification of medical images? In MATEC Web of Conferences (Vol. 76, p. 05002). EDP Sciences. https://doi. $\operatorname{org} / 10.1051 /$ matecconf/20167605002.

Hadzieva, E., Bogatinoska D. C., Shuminoska M., Petroski, R. (2017). On the reliability of the fractal dimension as a characteristic of the medical images contours. WSEAS Transactions on Biology and Biomedicine, 14, 19-28.

Lennon, F. E., Cianci, G. C., Cipriani, N. A., Hensing, T. A., Zhang, H. J., Chen, C. T. ... Salgia, R. (2015). Lung cancer a fractal viewpoint. Nature reviews Clinical oncology, 12(11), 664. https://dx.doi.org/10.1038\%2Fnrclinonc.2015.108

Lupo, M., Leguto, A. J., Bortolato, S. A., \& Korol, A. M. (2016). Evolution of erythrocytes aggregation: A fractal approach when incubated with Trichinella spiralis and Ascaris lumbricoides. Ain Shams Engineering Journal, 9(4), 1621-1625. https://doi.org/10.1016/j.asej.2016.12.004

Lv, D., Guo, X., Wang, X., Zhang, J., \& Fang, J. (2009). Computerized characterization of prostate cancer by fractal analysis in MR images. Journal of Magnetic Resonance Imaging: An Official Journal of the International Society for Magnetic Resonance in Medicine, 30(1), 161-168. https://doi.org/10.1002/jmri.21819

Macgillivray, T. J., Patton, N., Doubal, F. N., Graham, C., \& Wardlaw, J. M. (2007, August). Fractal analysis of the retinal vascular network in fundus images. In 29th Annual International Conference of the IEEE Engineering in Medicine and Biology Society, (pp. 6455-6458). IEEE. 10.1109/ IEMBS.2007.4353837

Mandelbrot, B. B. (1967). How long is the coast of Britain? Statistical self-similarity and fractional dimension. Science, 156(3775), 636-638. https:/doi. org/10.1126/science.156.3775.636

Mandelbrot, B. B. (1983). The fractal geometry of nature. New York, NY: W.H. Freeman and Company.

Pedraza, L., Vargas, C., Narváez, F., Durán, O., Muñoz, E., \& Romero, E. (2015, January). An open access thyroid ultrasound image database. In 10th International Symposium on Medical Information Processing and Analysis (Vol. 9287, p. 92870W). International Society for Optics and Photonics.

Savelonas, M., Maroulis, D., \& Sangriotis, M. (2009). A computer-aided system for malignancy risk assessment of nodules in thyroid US images based on boundary features. Computer Methods and Programs in Biomedicine, 96(1), 25-32. https://doi.org/10.1016/j.cmpb.2009.04.001

THEMA. . (2018, November 05). Retrieved from http://thema.univ-fcomte.fr/en/

Thyroid Digital Image Database. (2018, December 12). Retrieved from http://cimalab.intec.co/?lang=en\&mod=program\&id=5

Timbo, C., da Rosa, L. A. R., Goncalves, M., \& Duarte, S. B. (2009). Computational cancer cells identification by fractal dimension analysis. Computer Physics Communications, 180(6), 850-853. https://doi.org/10.1016/j.cpc.2008.12.011

Uahabi, K. L., \& Atounti, M. (2015). Applications of fractals in medicine. Annals of the University of Craiova-Mathematics and Computer Science Series, 42(1), 167-174.

Voinea, V., \& Popescu, D. (2011). Fractal analysis in electrography for biological systems diagnosing. UPB Sci Bull, 73, $29-42$. 